\title{
Intracellular Dialysis of Cyclic Nucleotides Induces Inward Currents in Turtle Vomeronasal Receptor Neurons
}

\author{
Mutsuo Taniguchi, Makoto Kashiwayanagi, and Kenzo Kurihara \\ Faculty of Pharmaceutical Sciences, Hokkaido University, Sapporo 060, Japan
}

Turtle vomeronasal receptor neurons in slice preparations were studied using the patch-clamp technique in the whole-cell and cell-attached configurations. The mean resting potential was -48 , and the response to an injected current step consisted of either a single spike or a train of spikes. An injected current of 3-30 pA was required to depolarize the neuron to spike threshold near $-50 \mathrm{mV}$. Voltage-clamped vomeronasal receptor neurons displayed transient inward currents followed by sustained outward currents in response to depolarizing voltage steps. Ir cell-attached recordings, $10 \mu \mathrm{M}$ forskolin added to the bath caused a transient increase of spike rate. Intracellular application of cAMP evoked an inward current in a dose-dependent manner from the neurons voltage clamped at $-70 \mathrm{mV} ; 0.1 \mathrm{~mm}$ cAMP was sufficient to elicit an inward current in the neurons. The magnitude of the response to cAMP reached a plateau at
$1 \mathrm{~mm}$ with an average peak amplitude of $176 \pm 34 \mathrm{pA}$. Intracellular application of $1 \mathrm{mM}$ cGMP also evoked an inward current with an average peak amplitude of $227 \pm 61 \mathrm{pA}$. The reversal potentials of the induced components were estimated to be $10 \pm 7 \mathrm{mV}$ for cAMP and $-4 \pm 16 \mathrm{mV}$ for cGMP. The reversal potential of the cAMP-induced current in external $\mathrm{Cl}^{-}$free solution was similar to that in normal Ringer's solution, suggesting that $\mathrm{Cl}^{-}$current is not significantly involved in the current. The present results represent the first evidence of cyclic nucleotide-activated conductance in the vomeronasal receptor membranes.

Key words: vomeronasal receptor neuron; transduction; second messenger; cAMP; cGMP; patch clamp; Lucifer yellow; turtle
The vomeronasal organ is a chemoreceptor system lacated at the base of the nasal septum of most terrestrial vertebrates. Whereas the olfactory receptor neurons have several long cilia, vomeronasal receptor neurons lack cilia and possess microvilli (Graziadei and Tucker, 1970; Hatanaka et al., 1982). The organ plays an important role in the execution of several species-typical behaviors, including those involved in feeding, social interaction, and reproduction (Powers and Winans, 1975; Rajendren and Dominic, 1985; Halpern, 1987; Wysocki and Meredith, 1987). Recently, Luo et al. (1994) tentatively identified G-proteins (Gs, $\mathrm{Gi}$, and $\mathrm{Go}$ ) in the vomeronasal tissue membrane preparations of garter snakes using immunoreactivity and ADP-ribosylation techniques and showed that both GTP $\gamma \mathrm{S}$ and forskolin increased the cAMP level in the neurons.

Despite these studies of their biological functions and biochemical properties, the electrophysiological properties of the vomeronasal receptor neurons have been examined only in the frog (Trotier et al., 1993). In the frog, voltage-activated $\mathrm{Na}^{+}$and $\mathrm{K}^{+}$ currents, a calcium-activated voltage-dependent $\mathrm{K}^{+}$current, and a voltage-dependent $\mathrm{Ca}^{2+}$ current were observed, and action potentials were elicited by depolarizing injected current pulses in the range of $2-10 \mathrm{pA}$. Application of cAMP to the frog vomeronasal receptor neurons failed to elicit a membrane current. Hence, no electrophysiological study has demonstrated the involvement of a cAMP-mediated pathway in the transduction process in vomeronasal receptor neurons.

\footnotetext{
Received Sept. 20, 1995; revised Nov. 13, 1995; accepted Nov. 20, 1995.

This work was supported by a Grant-in-Aid for Scicntific Rescarch from the Ministry of Education, Science and Culture, Japan. M.T. is a research fellow of the Japan Society for the Promotion of Science.

Correspondence should be addressed to Dr. Makoto Kashiwayanagi, Faculty of

Pharmaceutical Sciences, Hokkaido University, Sapporo 060, Japan.

Copyright (C) 1996 Society for Neuroscience $0270-6474 / 96 / 161239-08 \$ 05.00 / 0$
}

In the present study, we examined the electrophysiological features of turtle vomeronasal receptor neurons using whole-cell and cell-attached patch-clamp techniques. Intracellular dialysis of cAMP or cGMP into the neurons elicited a prolonged inward current. The present results represent the first clear evidence of cyclic nueleotide-activated conductance in the membrane of the vomeronasal receptor neurons.

\section{MATERIALS AND METHODS}

Slice preparation of vomeronasal epithelium. Turtles, Geoclemys reevesii, weighing 140-240 gm, were obtained from commercial suppliers and maintained at $22^{\circ} \mathrm{C}$. Turtles were anesthetized by cooling to $0^{\circ} \mathrm{C}$ and decapitated, after which the nasal cavities were opened and the vomeronasal neuroepithelia were dissected out. The epithelia were cut into slices $\sim 120 \mu \mathrm{m}$ thick with a vibrating slicer in normal Ringer's solution at $0^{\circ} \mathrm{C}$ and stored at $4^{\circ} \mathrm{C}$. Epithelial slices were fixed one at a time on the glass at the bottom of a recording chamber. This permits access to cells on the surface of the slice by the patch pipette. The preparations were viewed under an upright microscope (Optiphot, Nikon, Tokyo, Japan) using a $40 \times$ water immersion lens.

Electron microscopy. The vomeronasal neuroepithelia and slice preparations of $400 \mu \mathrm{m}$ thick were prepared as described above. After a quick rinse with Ringer's solution, the specimens were placed immediately in Karnovsky's fixative (Karnovsky, 1965), i.e., $5 \%$ glutaraldehydc/4\% formaldehyde in $100 \mathrm{~mm}$ sodium cacodylate buffer, $\mathrm{pH}$ 7.4. Fixation was performed at room temperature for at least one night. The tissues were postfixed in an aqueous solution of $1 \%$ osmium tetroxide for $2 \mathrm{hr}$ and dehydrated through a graded series of ethanol. After dehydration, the samples were critical-point dried from $\mathrm{CO}_{2}$ (model HCP-2, Hitachi Koki, Katsuta, Japan) and sputter-coated with gold (model IB-3, Eiko Engineering, Tokaimura, Japan) and then examined with a Hitachi S-430 scanning electron microscope (Hitachi, Tokyo, Japan) at $20 \mathrm{kV}$.

Data recording and analysis. Conventional whole-cell patch-clamp method was used to measure transmembrane currents (Hamill et al., 1981). Patch pipettes with resistances of 5-10 M $\Omega$ were made from borosilicate glass capillaries using a two-stage electrode puller (model PP853, Narishige, Tokyo, Japan) and then heat-polished. Membrane 
currents were recorded in the whole-cell configuration (holding potential, $-70 \mathrm{mV}$ ). Data were recorded continuously using an EPC-7 patch-clamp amplifier (List, Darmstadt, Germany) and stored on videocassette via a digital audio processor. All recordings were performed at room temperature. Data were filtered at $10 \mathrm{kHz}$ and digitized at $10 \mathrm{kHz}$. Analysis was performed on a personal computer using pClamp software (Axon Instruments, Foster City, CA). All values are given as mean \pm SEM.

Lucifer yellow dialysis. Lucifer yellow $\mathrm{CH}$ was dialyzed intracellularly in the same way as intracellular dialysis of cyclic nucleotides. For these experiments, tips of the patch pipettes containing a glass filament were filled with a $1 \%$ Lucifer yellow solution in normal internal solution containing $1 \mathrm{~mm}$ cAMP and/or $1 \mathrm{~mm}$ cGMP. At least $5 \mathrm{~min}$ after the beginning of dialysis, the pipettes were pulled back from the surface of the cells tested so that the membrane resealed. The specimens then were transferred to the stage of a fluorescent microscope (Optiphot, Nikon) and monitored by making observations with fluorescent illumination.

Solutions. Normal Ringer's solution consisted of (in mM): $116 \mathrm{NaCl}, 4$ $\mathrm{KCl}, 2 \mathrm{CaCl}_{2}, 1 \mathrm{MgCl}_{2}, 15$ glucose, 5 Na-pyruvate, 10 HEPES-NaOH, $\mathrm{pH}$ 7.4. For Cl-free Ringer's solution, $\mathrm{NaCl}, \mathrm{KCl}, \mathrm{CaCl}_{2}$, and $\mathrm{MgCl}_{2}$ were replaced by Na-gluconate, K-gluconate, Ca-gluconate, and $\mathrm{MgSO}_{4}$, respectively. Patch pipettes were filled with a normal internal solution (in $\mathrm{mM}$ ): $115 \mathrm{KCl}, 2 \mathrm{MgCl}_{2}, 10 \mathrm{HEPES}-\mathrm{KOH}, \mathrm{pH}$ 7.6. cAMP, cGMP, and a mixture of them were dissolved in the internal solution to desired final concentrations. Lucifer yellow was dissolved in the internal solution containing $1 \mathrm{mM}$ cAMP and/or $1 \mathrm{~mm}$ cGMP at a concentration of $1 \%$. The stock solutions of cAMP and cGMP at appropriate concentrations and $1 \%$ Lucifer yellow divided into $1.8 \mathrm{ml}, 1.8 \mathrm{ml}$, and $40 \mu \mathrm{l}$ aliquots were stored at $-80^{\circ} \mathrm{C}$ and thawed just before use, respectively. Stocked forskolin solution was prepared by dissolution in ethanol at $10 \mathrm{~mm}$, and appropriate volumes were added to the Ringer's solution to give the desired concentrations. These forskolin solutions were prepared daily. The final concentration of ethanol never exceeded $0.5 \%$. This concentration of ethanol alone had no measurable effect on the electrical properties of the neurons.

Gravity was used to deliver a constant stream of Ringer's solution from the stimulating tube. Two electrically actuated valves were used to switch irrigating Ringer's solution and a stimulating solution. The stimulating tube with a lumen $160-200 \mu \mathrm{m}$ in diameter was placed under visual control within $\sim 500 \mu \mathrm{m}$ of the neuron. To eliminate a nonspecific effect of the mechanical stimulation, a slice was irrigated with normal Ringer's solution at the same flow rate as that of stimulating solution just before application of the stimulating one. The concentrations of stimuli were represented as concentration in the pipette, and no correction for dilution was made.

Chemicals. cAMP, forskolin, cGMP, and Lucifer yellow $\mathrm{CH}$ were purchased from Boehringer Mannheim GmbH (Mannheim, Germany), Wako Pure Chemical Industries (Osaka, Japan), Yamasa Shoyu (Choshi, Japan), and Aldrich Chemical (Milwaukee, WI), respectively. All chemicals used were of the highest grade available.

\section{RESULTS}

\section{Cell morphology}

Transverse sections of the nasal cavity showed that the olfactory mucosa occupied the dorsal region and that the vomeronasal mucosa was located in the ventral region (Fig. 1). Vomeronasal receptor neurons are bipolar and have microvilli (Graziadei and Tucker, 1970; Hatanaka et al., 1982). The microvilli could not be identified with the optics used for viewing the electrophysiological preparations because they are only $100 \mathrm{~nm}$ in diameter (Hatanaka et al., 1982). Several microvilli ( $\sim 100 \mathrm{~nm}$ in diameter) extending from the terminal ends of the dendrite of receptor neurons could be seen by scanning electron microscopy (Fig. $1 D$ ).

Hatanaka and Hanada (1987) reported that three layers of supporting cells, receptor cells, and basal cells could be distinguished in transverse sections of the vomeronasal mucosa. Although these layers could not be distinguished clearly in transverse sections of our preparations, a layer rich in cell bodies having bipolar or ovoid shape was observed. Cells in this layer dialyzed with $1 \%$ Lucifer yellow had a morphology characteristic of vomeronasal receptor neurons (Fig. 2). A dendrite of the dialyzed cell projected to the epithelial surface where it terminated in a knob-like structure. All of these cells $(n=12)$ presented voltage-dependent currents similar to those shown in Figure 3. In addition, cyclic nucleotide-induced current was simultaneously observed in four of five of these cells. We examined electrical properties of bipolar and ovoid neurons located in this layer in the slices.

\section{Resting potential}

With normal internal solution in the pipette, turtle vomeronasal receptor neurons maintained resting potentials ranging from -33 to $-72 \mathrm{mV}(-48 \pm 1 \mathrm{mV} ; n=41)$. The input resistance was measured from the responses to injected currents of $1 \mathrm{sec}$ ranging from -20 to $+20 \mathrm{pA}$ in $20 \mathrm{pA}$ increments applied at the holding potential of $-70 \mathrm{mV}$ and ranged from 0.7 to $2.8 \mathrm{G} \Omega(1.7 \pm 0.1$ $\mathrm{G} \Omega ; n=14)$.

\section{Voltage responses to injected current}

In current-clamp recordings, the membrane potentials of the neurons were maintained at $-70 \mathrm{mV}$ by injecting hyperpolarizing current. Step depolarization induced by stimulus current from a holding current produced an action potential (Fig. 3A). Twentyfive of $30(83 \%)$ neurons fired one to several action potentials in response to current steps of $<30 \mathrm{pA}$ from the conditioning current that maintains the membrane potential at approximately -70 $\mathrm{mV}$. The threshold for action potential generation in vomeronasal receptor neurons was commonly between -45 and $-61 \mathrm{mV}$ with a mean threshold potential of $50 \pm 2 \mathrm{mV}$. A variety of spiking patterns was seen, ranging from neurons that fired only a single action potential for any suprathreshold stimulus (data not shown) to those that generated brief trains of action potentials. In the example shown in Figure $3 B$, the action potentials were generated repetitively in response to a depolarizing current pulse of $23 \mathrm{pA}$. Neurons required current injection varying from only 3 pA to 30 pA to depolarize to spike threshold (data not shown), suggesting that vomeronasal receptor neurons in turtle are highly sensitive to injected currents similar to those in the frog (Trotier et al., 1993).

\section{Whole-cell current}

Figure $3 \mathrm{C}$ shows the two major currents elicited by depolarizing steps of voltage from a holding potential of $-70 \mathrm{mV}$. A transient inward current activated at $-40 \mathrm{mV}$ became larger, faster, and more transient with higher depolarizing steps reaching up to $1 \mathrm{nA}$ at $-20 \mathrm{mV}$. The current-voltage $(I-V)$ curves taken at the peak of the inward current and during the sustained portion of the outward current are shown in Figure $3 D$. Outward currents were activated near $-40 \mathrm{mV}$ and display inactivation during a $60 \mathrm{msec}$ step.

\section{Increase in impulse frequency in response to forskolin}

To examine whether there is a cAMP-mediated signal transduction pathway in the vomeronasal receptor neurons, the responses to forskolin, a direct activator of adenylyl cyclase, were recorded in turtle vomeronasal receptor neurons using the cell-attached configuration. As shown in Figure $4 A$, before application of $10 \mu \mathrm{M}$ forskolin, the vomeronasal receptor neurons generate spikes spontaneously with very low frequency ( 3 impulses per $10 \mathrm{sec}$ interval). After the application, spike rate became higher (46 impulses per $10 \mathrm{sec}$ interval). Forskolin induced such increases in spike frequency in four of six neurons. After the epithelium was washed with normal Ringer's solution, reapplication of forskolin increased impulse frequency in three of four neurons. These 
A

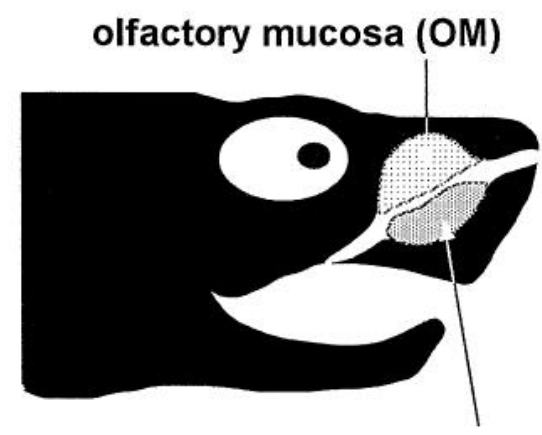

vomeronasal mucosa (VM)

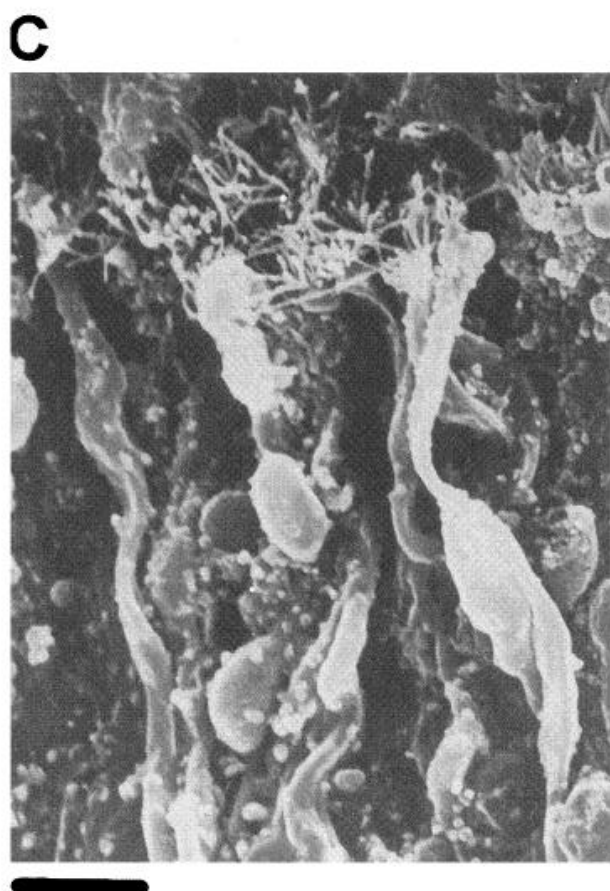

$5 \mu \mathrm{m}$
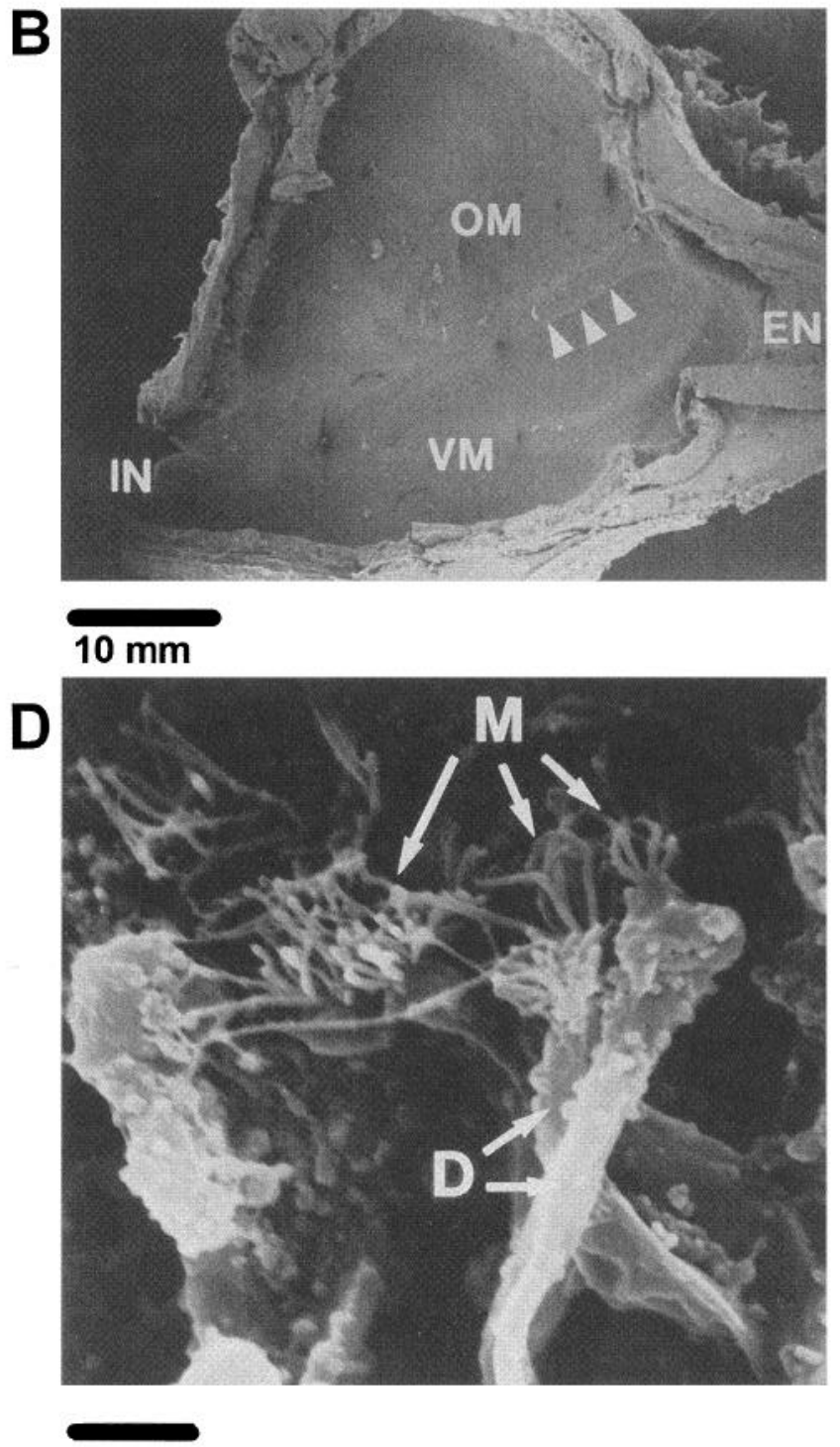

$2 \mu \mathrm{m}$

Figure 1. The nasal cavity of the stink turtle. A, Schematic drawing of a sagittal section of a turtle nasal cavity corresponding to scanning electron micrograph. $B$, Low-magnification scanning micrograph of a sagittal section of turtle nasal cavity. There is a ridge-like structure indicated by arrowheads in the middle portion of the cavity. This ridge-like structure entirely separates the vomeronasal mucosa from the olfactory mucosa. That is, the olfactory mucosa occupied the dorsal region and the vomeronasal mucosa was located in the ventral region. These two types of mucosa could be distinguished easily from their surface structure. $E N$, External nares; $I N$, internal nares; $O M$, olfactory mucosa; $V M$, vomeronasal mucosa. Lateral aspect of vomeronasal epithelium $(C)$ and detailed view of microvilli at terminals of dendrites $(D)$. The dendrites of receptor neurons extended from round soma to the mucosal surface through the supporting cell layer, and their terminals were a little swollen. The higher-magnification scanning micrograph $(D)$ taken from the same field as that in $C$ clearly demonstrates that the terminals of the receptor neuron dendrites possess a number of microvilli. $D$, receptor neuron dendrite; $M$, microvilli of the receptor neuron.

results suggested the existence of adenylyl cyclase and cAMPdependent ion channels in the vomeronasal receptor neurons.

\section{Transient inward current induced by cAMP}

To confirm the existence of cAMP-dependent conductance in vomeronasal receptor neurons, cAMP was introduced into a proximal part of the dendrite or a part of the cell soma using wholecell configuration. Figure $4 B$ shows the currents induced by intracellular dialysis of cAMP at varying concentrations into vomeronasal receptor neurons. When the pipette was filled with a cAMP-free inner solution, the neurons held a steady baseline over the test interval of $\sim 3-10 \mathrm{~min}$ after membrane rupture. On the other hand, introduction of cAMP into the neurons evoked pro- longed inward currents within a few seconds after membrane rupture. The magnitudes of the responses to cAMP introduced intracellularly increased with increases in their concentrations.

In the present study, 30 neurons were stimulated by $1 \mathrm{~mm}$ cAMP. Twenty-one neurons $(70 \%)$ displayed an increase in the inward current with adaptation of current after the peak response. The amplitude of the inward current induced by cAMP varied from 0 to $756 \mathrm{pA}(176 \pm 34 \mathrm{pA} ; n=30)$. The dispersion in the current amplitudes probably reflects cellular differences. In some neurons, the cAMP-induced current was not adapted. The data obtained from these neurons were excluded because it was unclear whether the current observed represented an inward current 


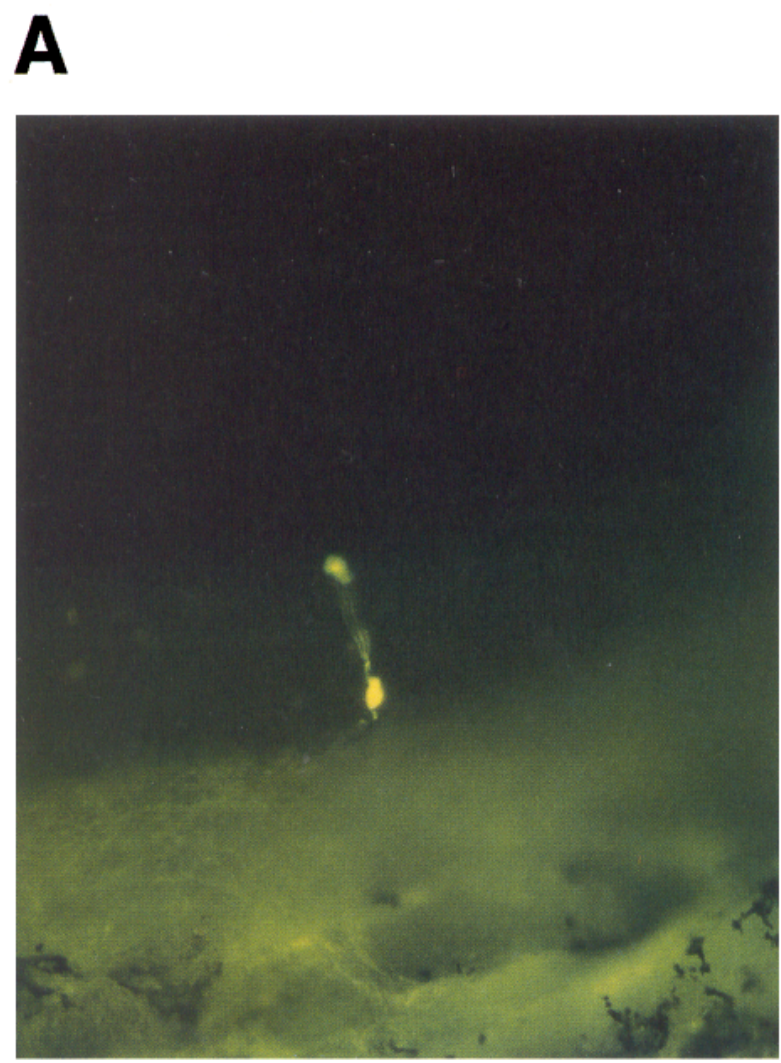

$100 \mu \mathrm{m}$
B

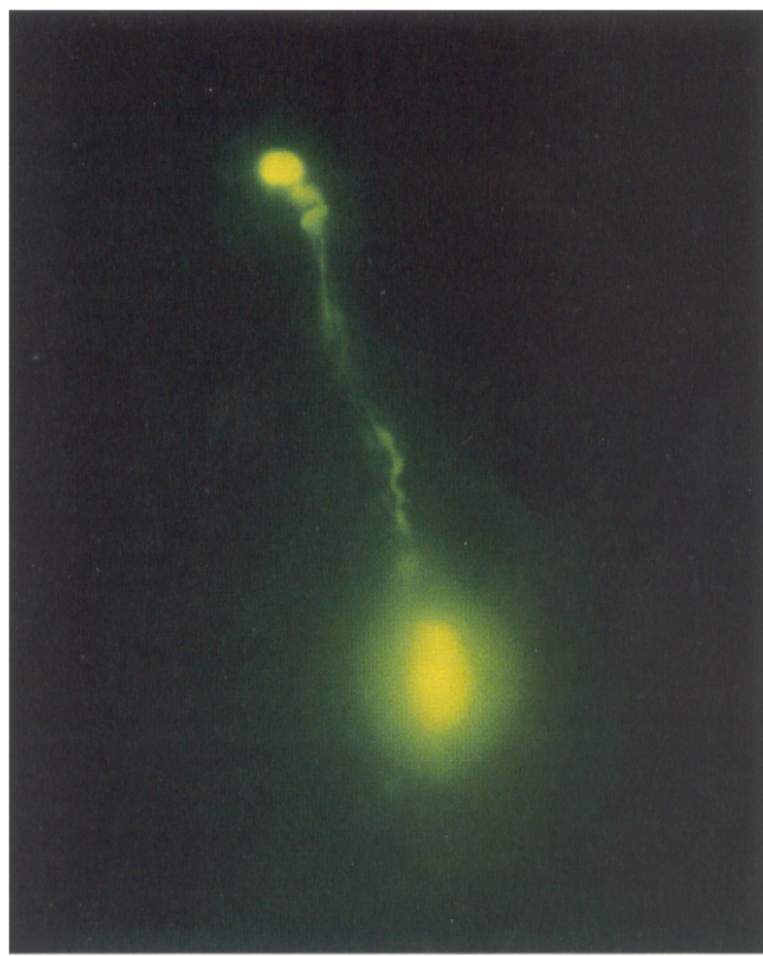

$25 \mu \mathrm{m}$

Figure 2. A receptor neuron identified by its morphology and electrical characteristics. The neuron was dialyzed with $1 \%$ Lucifer yellow. $A$, Fluorescence micrograph of a slice of a vomeronasal epithelium. The dendrite, cell body, and a part of the axon are visible. $B$, Higher-magnification fluorescence micrograph focused on the terminal of the dendrite. Enlargement from the same field as that in $A$.

induced by cAMP or artificial leakage. We also excluded the data obtained from these cells that made no response to depolarizing voltage steps from a holding potential of $-70 \mathrm{mV}$ after or before intracellular dialysis of cyclic nucleotides.

Kashiwayanagi et al. (1994) applied $1 \mathrm{~mm}$ cAMP into turtle olfactory neurons and observed induction of an inward current with an average peak amplitude of $252 \pm 30 \mathrm{pA}(n=31)$. Thus, the magnitude of the response induced by cAMP in the turtle vomeronasal receptor neurons was similar to that in the turtle olfactory neurons. The time-to-peak for the response of the vomeronasal neurons varied from 5 to $102 \sec (28 \pm 5 \mathrm{sec} ; n=30)$. This time was slower than that for the cAMP-induced response of the newt olfactory neurons (near $4 \mathrm{sec}$ ) (Kurahashi, 1990), but similar to that of turtle olfactory neurons $(26 \pm 4$ sec; $n=22)$ (Kashiwayanagi et al., 1994).

Figure $4 C$ shows the magnitudes of the responses induced by intracellular application of cAMP plotted as a function of cAMP concentration. The present method of nucleotide application allowed administration of only a single dose to each neuron. The cumulative results from many neurons are shown in Figure $4 C$. The currents started to appear between 0 and $0.1 \mathrm{~mm}$, increased with increasing cAMP concentrations, and reached a plateau at 1 $\mathrm{mm}$. This dose dependence was similar to that reported previously in isolated olfactory neurons of the newt (Kurahashi, 1990) and turtle (Kashiwayanagi and Kurihara, 1995).

\section{Voltage dependence of cAMP-induced response}

The $I-V$ relationships were examined by applying a voltage ramp from -70 to $+50 \mathrm{mV}(480 \mathrm{mV} / \mathrm{sec})$ to voltage-clamped vomeronasal neurons before, during, and after the response induced by cAMP. The $I-V$ relationship measured before the response induced by intracellular dialysis of cAMP into neurons was similar to that measured in control cells with normal internal solution (data not shown). As shown in Figure 5, the slope of the $I-V$ curve measured during the cAMP-induced response was steeper than that measured before the response, indicating that cAMP increases the membrane conductance. Because a voltage-sensitive current is activated near $-40 \mathrm{mV}$ as shown in Figure 3, we estimated the reversal potential of the cAMP-induced current from the intersection of the lines that were fitted by least-squares regression through the points involved in straight part of the traces at negative membrane potentials less than $-40 \mathrm{mV}$. The reversal potential was estimated to be $10 \pm 7 \mathrm{mV}(n=12)$, which was more positive than the potentials observed with isolated newt olfactory neurons (Kurahashi, 1990), patch membranes excised from the cilia of the frog (Nakamura and Gold, 1987), and olfactory knob of the frog and rat (Frings et al., 1992).

Under the experimental conditions used in Figure 5, the reversal potentials for nonspecific cationic channels are similar 

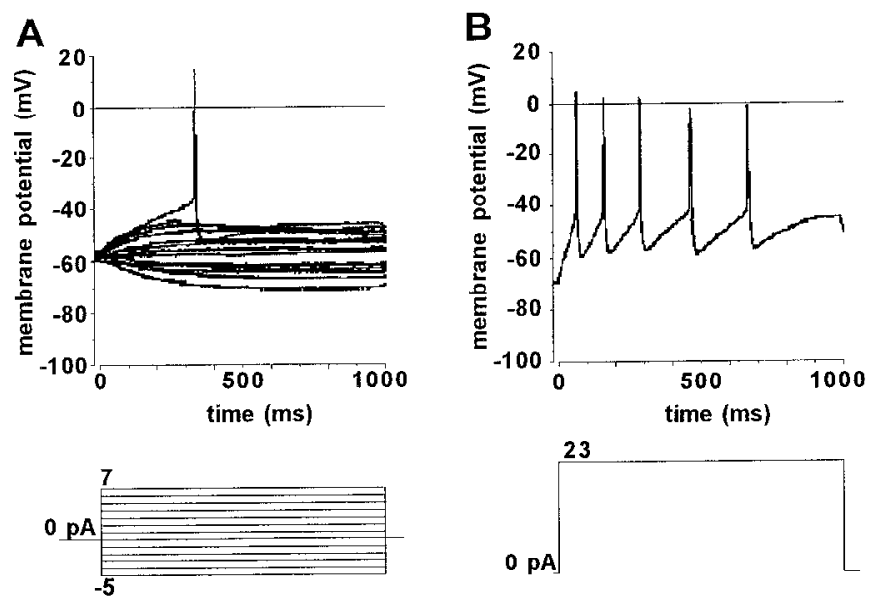

C
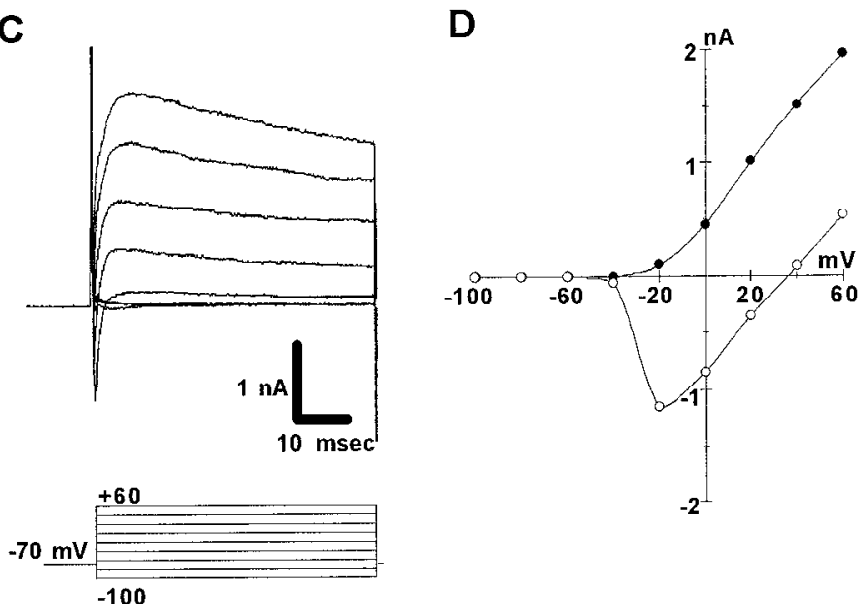

Figure 3. Electrical responses of a vomeronasal receptor neuron. $A$, Voltage response to current steps between -5 and $7 \mathrm{pA}$ (in $1 \mathrm{pA}$ increments). Resting level of this neuron was $-70 \mathrm{mV}$ and threshold was near $-55 \mathrm{mV} . B$, Voltage response of the same neuron to a current step of $23 \mathrm{pA}$. In every case in which the action potentials were generated repetitively, the interval between the few spikes increased with each subsequent spike $(n=3)$. Bottom traces show the corresponding current pulse. $C$, Typical whole-cell currents in a vomeronasal receptor neuron in a slice preparation in response to voltage steps. Step levels arc shown in the bottom traces. Transient inward and delayed outward currents were elicited in response to $60 \mathrm{msec}$ voltage steps between -100 and $60 \mathrm{mV}$ in $20 \mathrm{mV}$ increments from a holding potential of $-70 \mathrm{mV} . D, I-V$ relationships of peak inward currents (open circles) and $60 \mathrm{msec}$ after the onset of the voltage step during the sustained plateau of the outward current (filled circles) measured from the records in $C$. The pipette contained normal internal solution, and the bath contained Ringer's solution.

to those for chloride channels. Therefore, it is possible that chloride current is involved in the cAMP-induced response. We checked involvement of chloride in the cAMP-induced response in the turtle vomeronasal neurons. As shown in Figure 6 , bathing the neurons in an external solution containing no $\mathrm{Cl}$ had little effect on cAMP-evoked inward currents. The mean peak amplitude of the current induced by $1 \mathrm{mM}$ cAMP was reduced slightly from $176 \pm 34 \mathrm{pA}(n=30)$ to $154 \pm 44 \mathrm{pA}$ $(n=10)$. The mean reversal potential of the cAMP-evoked current was estimated to be $-10 \pm 8 \mathrm{mV}(n=6)$. The reversal potential in $\mathrm{Cl}^{-}$-free Ringer's solution was smaller than that in normal Ringer's solution but statistically not significant. The results suggest that chloride current is not involved significantly in the cAMP-induced response.

\section{Transient inward current induced by cGMP and its voltage dependence}

Figure 7 shows the currents induced by intracellular dialysis of cGMP of varying concentrations into vomeronasal receptor neurons. cGMP was introduced in the same manner as cAMP. Application of $1 \mathrm{mM}$ cGMP to the neurons evoked inward currents within a few seconds after membrane rupture in 8 of $10(80 \%)$ neurons. The amplitude of the inward current induced by cGMP varied from 0 to $555 \mathrm{pA}(227 \pm 61 \mathrm{pA})$. The data obtained from the neurons in which the cGMP-induced current was not adapted were excluded. The time-to-peak for the response of the vomeronasal neurons varied from 4 to $55 \sec (28 \pm 7 ; n=8)$, similar to that for the cAMP-induced response.

Figure $7 C$ shows the voltage dependence of the cGMP-induced currents examined by applying a voltage ramp from -100 to \pm 60 $\mathrm{mV}(43.7 \mathrm{mV} / \mathrm{sec})$ to voltage-clamped neurons during and after the response induced by $1 \mathrm{~mm}$ cGMP. The slope of the $I-V$ curve measured during the cGMP-induced response was steeper than that measured after the response, suggesting that cGMP increases membrane conductance. The reversal potential was estimated to be $-4 \pm 16 \mathrm{mV}(n=5)$ and was similar to that observed in response to intracellular application of cAMP as shown in Figure 5 .

'To examine whether cAMP and cGMP activate the same conductance in vomeronasal receptor neurons, an internal solution containing cAMP and cGMP at $1 \mathrm{~mm}$ cach was dialyzed into the neurons and the evoked current response was measured. Simultaneous intracellular dialysis of cAMP and cGMP into the neurons elicited an inward current in 19 of 29 neurons (data not shown). The mean amplitude of the response induced by simultaneous intracellular dialysis of cAMP and cGMP at $1 \mathrm{~mm}$ each was $205 \pm 47.5 \mathrm{pA}$, which was similar to that induced by intracellular dialysis of $1 \mathrm{~mm}$ cAMP or cGMP alone.

\section{DISCUSSION}

\section{Electrophysiological properties of the turtle vomeronasal receptor neurons}

The mean resting potential of turtle vomeronasal receptor neurons was $-48 \mathrm{mV}$, less negative than that of these cells in frog, which was reported to be approximately $-61 \mathrm{mV}$ (Trotier et al., 1993). In olfactory neurons of the frog (Trotier, 1986), salamander (Fire-stein and Werblin, 1987), newt (Kurahashi and Shibuya, 1990), and rat (Okada et al., 1994), the resting potentials were $-40,-55,-44$, and $-48 \mathrm{mV}$, respectively. Thus, it appears that turtle vomeronasal receptor neurons have similar resting potentials to olfactory neurons of other species. Input resistance of the receptor neurons that were observed in this study was near 1.7 $\mathrm{G} \Omega$. This value is slightly lower than that of olfactory neurons, which was reported to be near 2-10 G $\Omega$ (Firestein and Werblin, 1987; Trotier et al., 1993; Okada et al., 1994), but it is not significantly different.

The present results showed that the transient inward currents activated at $-40 \mathrm{mV}$ reached a peak at approximately $-20 \mathrm{mV}$ (Fig. 3) followed by sustained outward currents that were activaled at $-40 \mathrm{mV}$ and slightly inactivated. These properties are similar to those measured in isolated frog vomeronasal receptor neurons in which a transient fast inward current activating near $-45 \mathrm{mV}$ was blocked by tetrodotoxin, and an outward $\mathrm{K}^{+}$current was blocked by internal $\mathrm{Cs}^{+}$or by external tetraethylammonium or $\mathrm{Ba}^{2+}$ (Trotier et al., 1993). A detailed analysis of these voltageactivated currents was not performed in the present study, but the 

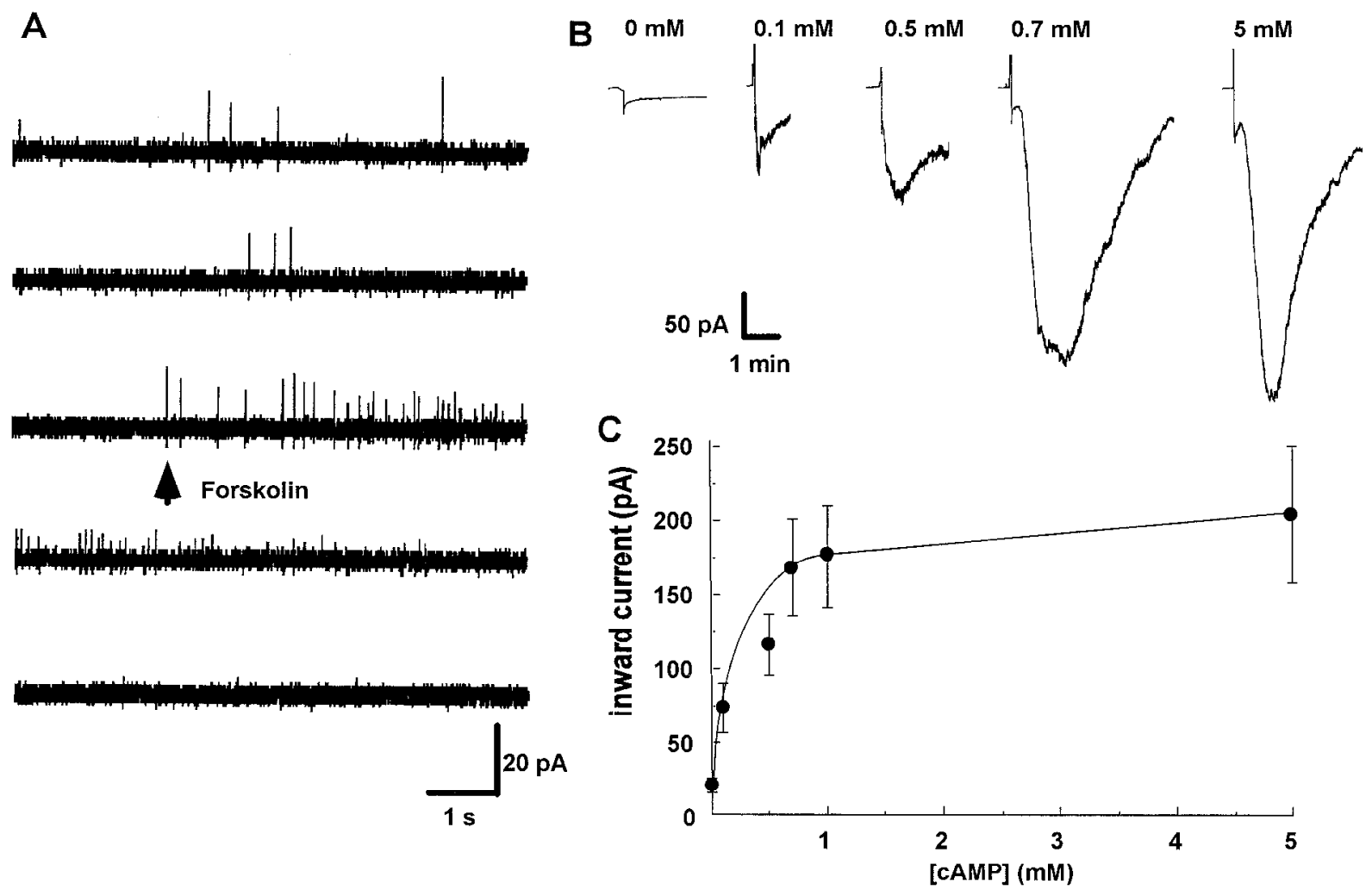

Figure 1. A, Cell attached extracellular recordings of a single turtle vomeronasal receptor ncuron in situ. The arrowhead represents time of application of $10 \mu \mathrm{M}$ forskolin. $B$, Response induced by intracellular application of cAMP from the patch pipette to a vomeronasal receptor neuron bathed in normal Ringer's solution. The concentrations of cAMP contained in the pipette are shown at the top of each trace. Holding potential, $-70 \mathrm{mV}$. $C$, Duse-dependence of the response induced by intracellular dialysis of cAMP into turtle vomeronasal receptor neurons. Each point represents the mean \pm SEM of data obtained from at least 23 neurons. The curve was fitted by eye.

transient inward currents and the outward currents were identified tentatively as $\mathrm{Na}^{+}$and $\mathrm{K}^{+}$currents, respectively.

The properties of the transient inward currents measured in turtle vomeronasal receptor neurons also were consistent with those measured in rat olfactory neurons (Okada et al., 1994), rat olfactory neurons in culture (Trombley and Westbrook, 1991), and salamander olfactory neurons (Firestein and Werblin, 1987). Outward currents observed in the present study displayed a voltage dependence similar to those found in isolated rat olfactory neurons (Lynch and Barry, 1991; Trombley and Westbrook, 1991; Rajendra et al., 1992; Okada et al., 1994).

As a result of the high input resistance of the turtle vomeronasal receptor neurons, an injected current of only 3 pA was required to reach spike threshold. This is similar to the case of frog vomeronasal neurons (Trotier et al., 1993). The sensitivity of the turtle vomeronasal receptor neurons to injected currents also was comparable to that of the rat olfactory neurons (Lynch and Barry, 1989).

The results described above indicate that turtle vomeronasal receptor neurons are similar to frog vomeronasal receptor neurons and olfactory neurons of other species with regard to their passive electrical characteristics, being electrotonically compact and possessing a low spike threshold, and in their spike responses and the gated currents underlying these responses.

\section{Response induced by cyclic nucleotides}

The present study clearly demonstrated that the turtle vomeronasal receptor neurons respond to intracellular dialysis of cAMP with an increase in inward current at negative membrane poten- tials in a dose-dependent manner. In the neurons, cAMP induced an inward current accompanied by an increase in conductance (Fig. 5). The reversal potential of the cAMP-induced current was

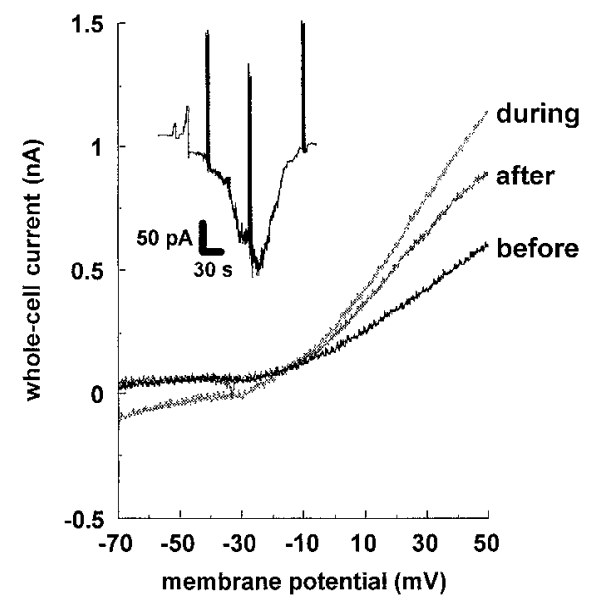

Figure 5. Whole-cell $I-V$ relationships for the current evoked by intracellular application of $0.5 \mathrm{~mm}$ cAMP. The current was measured by applying a voltage ramp $(480 \mathrm{mV} / \mathrm{sec})$ from -70 to $+50 \mathrm{mV}$ before, during, and after the response induced by $0.5 \mathrm{~mm}$ cAMP. These traces were obtained from the same cell. The inset shows the record of the cAMP-induced response of this cell under whole-cell voltage-clamp conditions at $-70 \mathrm{mV}$. The current transients were produced by voltage ramps $(480 \mathrm{mV} / \mathrm{sec})$ from -70 to $+50 \mathrm{mV}$. The reversal potential of the current induced by intracellular application of $0.5 \mathrm{mM}$ cAMP to this neuron was estimated to be $-16.5 \mathrm{mV}$. 


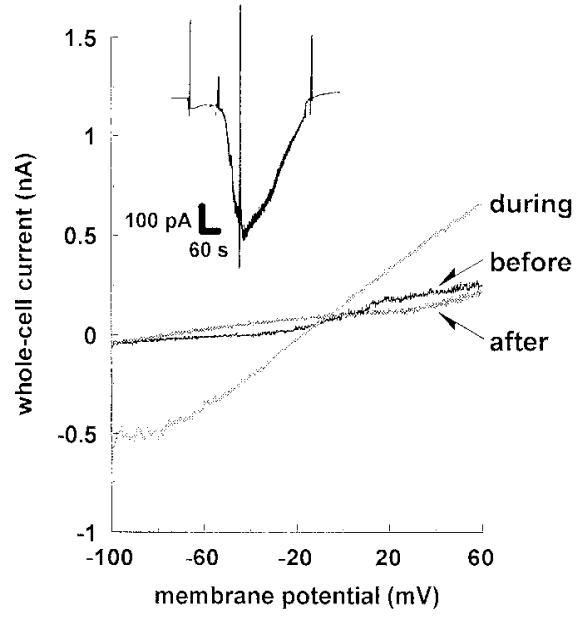

Figure 6 . Whole-cell $I-V$ relationships for the current evoked by intracellular application of $1 \mathrm{~mm}$ cAMP. The cell was bathed in $\mathrm{Cl}$-free Ringer's solution. The current was measured by applying a voltage ramp (43.7 mV/sec) from -100 to $+60 \mathrm{mV}$ before, during, and after the response induced by $1 \mathrm{mM}$ cAMP. These traces were obtaincd from the sane cell. The inset shows the record of the cAMP-induced response of this cell under whole-cell voltagc-clamp conditions at $-70 \mathrm{mV}$. The current transients were produced by voltage ramps $(43.7 \mathrm{mV} / \mathrm{sec})$ from -100 to $+60 \mathrm{mV}$. The reversal potential of the current induced by intracellular application of $1 \mathrm{mM}$ cAMP to this neuron was estimated to be $-7.6 \mathrm{mV}$.

near $0 \mathrm{mV}$ and practically unaffected by removal of external Cl , suggesting the possibility that the cAMP-induced current found in this study is evoked via cation nonspecific cyclic nucleotide-gated channels. Intracellular dialysis of cGMP into the turtle vomeronasal receptor neurons also elicited inward currents similar to cAMP with regard to the peak amplitude and the reversal potential of the responses. In addition, the mean amplitude of the response induced by simultaneous intracellular dialysis of $1 \mathrm{~mm}$ cAMP and $1 \mathrm{mM}$ cGMP into turtle vomeronasal receptor ncurons was similar to that induced by cAMP or CGMP at the concentration of $1 \mathrm{~mm}$, at which the cAMP-induced response reached a plateau. These results suggest that the two nucleotides that act on the same channels as seen in cyclic nucleotide-gated channels found in turtle vomeronasal àre similar to those found in many vertebrate olfactory neurons (Trotier and MacLeod, 1986; Nakamura and Gold, 1987; Suzuki, 1989; Bruch and Teeter, 1990; Firestein ct al., 1991; Frings et al., 1992).

In the frog, intracellular dialysis of cAMP into vomeronasal receptor neurons failed to elicit a membrane current (Trotier et al., 1993). The disagreement between the results of this previous and the present study may have been attributable to the difference in species of animal used. Alternatively, the discrepancy may have been attributable to the differences in the type of preparation used; we examined neurons in slice preparations, whereas Trotier et al. (1994) used enzymatically isolated vomeronasal neurons. It is possible that enzymatic dissociation of the neurons inflicts unintentional damage on channel activities.

In the turtle vomeronasal organ, neither a chemoattractant nor a substance that activates the cAMP cascadc has bcen identified. Therefore, the biological roles of cAMP channcls found in the present study arc unknown. In the garter snake, the chemoattractant ES20 (Jiang et al., 1990) was suggested to couple with the G-proteins Gs, Gi, and Go (Luo et al., 1994). Both GTP $\gamma S$ and forskolin increased the cAMP level in snake vomeronasal neurons (Luo et al.,
A
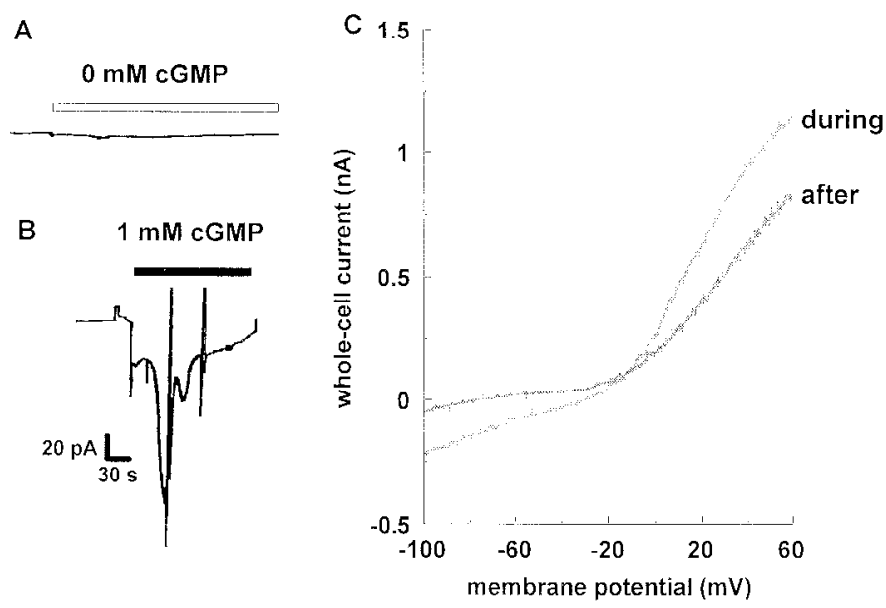

Figure 7. $A$, Response induced by intracellular application of $0 \mathrm{~mm}$ cGMP (normal internal solution) from the patch pipette to a vomeronasal receptor neuron bathed in normal Ringer's solution (control). B, Response induced by intracellular application of $1 \mathrm{~mm}$ cGMP from the patch pipette to a vomeronasal receptor neuron bathed in normal Ringer's solution. The current transients were produced by applying voltage ramps $(43.7 \mathrm{mV} / \mathrm{sec})$ from -100$)$ to $+60 \mathrm{mV}$. Open and solid bars above traces indicate period of intracellular dialysis of 0 and 1 mM cGMP in normal internal solution, respectively. Holding potential, $-70 \mathrm{mV}$. C. Whole-cell $I-V$ relationships for the current evoked by intracellular application of 1 mm eGMP. The current was measured by applying a voltage ramp (43.7 $\mathrm{mV} / \mathrm{sec}$ ) from -100 to $+60 \mathrm{mV}$ during and after the response induced by 1 mM cGMP. These traces were obtained from the same cell. The reversal potential of the current induced by intracellular application of $1 \mathrm{~mm}$ cGMP to this neuron was estimated to be $-5.3 \mathrm{mV}$.

1994). The present results, together with these observations, support the idea that the cAMP pathway is involved in the transduction of environmental chemical stimuli in the vomeronasal organ.

Luo et al. (1994) also reported that the binding of ES20 to its reccptors in the snake vomeronasal ncurons increased inositol 1,4,5trisphosphate $\left(\mathrm{IP}_{3}\right)$ lcvels. In a previous study (Taniguchi et al., 1995), we found that intracellular application of $\mathrm{IP}_{3}$ to turtle vomeronasal receptor neurons cvoked a prolonged inward current and that this current was inhibited by extcrnal ruthenium red, demonstrating that the membranes of these neurons possess $\mathrm{IP}_{3}$-activated conductance. These observations suggest that the $\mathrm{IP}_{3}$-mediated pathway also is involved in the transduction of chemoattractant signals.

\section{REFERENCES}

Bruch RC, Tecter JH (1990) Cyclic AMP links amino acid chemoreception to ion channels in olfactory cilia. Chem Senses 15:419-430.

Firestein S, Darrow B. Shepherd GM (1991) Activation of the sensory current in salamander olfactory receptor neurons depends on a $G$ protein-mediated cAMP second messenger system. Neuron 6:825-835.

Firestein S, Werblin F (1987) Gated currents in isolated olfactory receptor neurons of the larval tiger salamander. Proc Natl Acad Sci USA 84:6292-6296

Frings S, Lynch JW, Lindemann B (1992) Propertics of cyclic nucleotidegated channels mediating olfactory transduction. Activation, selectivity, and blockige. J Gen Physiol 100:45-67.

Graziadei PPC, Tucker D (1970) Vomeronasal receptors in turtles. Z Zellforsch Mikrosk Anat 105:498-514.

Halpern M (1987) The organization and function of the vomeronasal systcm. Annu Rev Ncurosci 10:325-362.

Hamill OP, Marty A, Neher E, Sackmann B, Sigworth EJ (1981) Improved patch-clamp techniques for high-resolution current recording from cells and cell-free membrane patches. Pfügers Arch 391:85-100.

Hatanaka T, Hanada T (1987) Structure of the vomeronasal system and induced wave in the accessory olfactory bulb of red eared turtle. Chem Sonses 12:521. 
Hatanaka T, Matsuzaki O, Shibuya T (1982) Fine structure of vomeronasal receptor cells in the reeve's turtle, Geoclemys reevesii. Zool Mag 91:190-193.

Jiang XC, Inouchi J, Wang D, Halpern M (1990) Purification and characterization of a chemoattractant from electric shock-induced earthworm secretion, its receptor binding, and signal transduction through the vomeronasal system of garter snakes. J Biol Chem 265:8736-8744.

Karnovsky MJ (1965) A formaldehyde-glutaraldehyde fixative of high oskmolarity for use in electron microscopy. J Cell Biol 27:137-138.

Kashiwayanagi M, Kurihara K (1995) Odor responses after complete desensitization of the cAMP-dependent pathway in turtle olfactory cells. Neurosci Lett 193:61-64.

Kashiwayanagi M, Kawahara H, Hanada T, Kurihara K (1994) A large contribution of a cyclic AMP-independent pathway to turtle olfactory transduction. J Gen Physiol 103:957-974.

Kurahashi T (1990) The response induced by intracellular cyclic AMP in isolated olfactory receptor cells of the newt. J Physiol (Lond) 430:355-371.

Kurahashi T, Shibuya T (1990) $\mathrm{Ca}^{2+}$-dependent adaptive properties in the solitary olfactory receptor cell of the newt. Brain Res 515:261-268.

Luo Y, Lu S, Chen P, Wang D, Halpern M (1994) Identification of chemoaltractant receptors and G-proteins in the vomeronasal system of garter snakes. J Biol Chem 269:16867-16877.

Lynch JW, Barry PH (1989) Action potentials initiated by single channels opening in a small neuron (rat olfactory receptor). Biophys $\mathbf{J}$ 55:755-768.

Lynch JW, Barry PH (1991) Properties of transient $\mathrm{K}^{+}$currents and underlying single $\mathrm{K}^{+}$channels in rat olfactory receptor neurons. $\mathbf{J}$ Gen Physiol 97:1043-1072.

Nakamura T, Gold GH (1987) A cyclic nucleotide-gated conductance in olfactory receptor cilia. Nature 325:442-444.

Okada Y, Teeter JH, Restrepo D (1994) Inositol 1,4,5-trisphosphate-gated conductance in isolated rat olfactory neurons. J Neurophysiol 71:595-602.
Powers JB, Winans SS (1975) Vomeronasal organ: critical role in mediating sexual behavior of the male hamster. Science 187:961-963.

Rajendra S, Lynch JW, Barry PH (1992) An analysis of $\mathrm{Na}^{+}$currents in rat olfactory receptor ncurons. Pflugers Arch 420:342-346.

Rajendren G, Dominic CJ (1985) Effect of bilateral transection of the lateral olfactory tract on the male-induced implantation failure (the Bruce effect) in mice. Physiol Behav 36:587-590.

Suzuki N (1989) Voltage- and cyclic nucleotide-gated currents in isolated olfactory receptor cells. In: Chemical senses, receptor events and transduction in taste and olfaction (Brand JG, Teeter JH, Cagan RH, Kare MR, eds), pp 469-493. New York: Dekker.

Taniguchi M, Kashiwayanagi M, Kurihara K (1995) Intracellular injection of inositol 1,4,5-trisphosphate increases a conductance in membranes of turtle vomeronasal receptor neurons in the slice preparation. Neurosci Lett 188:5-8.

Trombley PQ, Westbrook GL (1991) Voltage-gated currents in identified rat olfactory receptor neurons. J Neurosci 11:435-444.

Trotier D (1986) A patch-clamp analysis of membrane currents in salamander olfactory receptor cells. Pflugers Arch 407:589-595.

Trotier D, MacLeod P (1986) cAMP and cGMP open channels and depolarize olfactory receptor cells. Chem Senses 11:674.

Trotier D, Døving KB, Rosin J-F (1993) Voltage-dependent currents in microvillar receptor cells of the frog vomeronasal organ. Eur J Neurosci 5:995-1002.

Trotier D, Døving KB, Rosin J-F (1994) Functional properties of frog vomeronasal receptor cells. In: Olfaction and taste XI (Kurihara K, Suzuki N, Ogawa H, eds), pp 188-191. Tokyo: Springer.

Wysocki CJ, Meredith M (1987) The vomeronasal system. In: Neurobiology of taste and smell (Finger TE, Silver WL, eds), pp 125-150. New York: Wiley. 